\title{
ENERGY EXPENDITURE AND PERCEIVED EXERTION DURING ACTIVE VIDEO GAMES IN RELATION TO PLAYER MODE AND GENDER
}

\author{
Giuseppe Francesco Giancotti ${ }^{1}$, Andrea Fusco', Angelo Rodio ${ }^{1}$, \\ Laura Capranica ${ }^{2}$, and Cristina Cortis ${ }^{1}$ \\ ${ }^{1}$ Department of Human Sciences, Society and Health, \\ University of Cassino e Lazio Meridionale, Cassino, Italy \\ ${ }^{2}$ Department of Movement, Human and Health Sciences, \\ University of Rome "Foro Italico", Rome, Italy
}

Original scientific paper

https://doi.org/10.26582/k.50.1.3

UDC: $612: 793.7$

\begin{abstract}
:
Active video games (AVG) increase energy expenditure (EE) with respect to sedentary video games. Although several AVG consoles allow playing in single-player (SP) or multiplayer (MP) mode, few studies investigated differences in relation to game modality in men and women. Therefore, the aim of this study was to evaluate gender-related psycho-physiological responses during Zumba Fitness Rush (ZFR) played in SP vs. MP mode. Twenty-four college students (women: 14, men: 10; age: $24.6 \pm 2.0$ years; body weight: $60.2 \pm 12.5 \mathrm{~kg}$; body height: $167.8 \pm 11.5 \mathrm{~cm}$; BMI: $21.2 \pm 2.1 \mathrm{~kg} \cdot \mathrm{m}^{-2}$ ) participated in two experimental sessions: SP (a subject playing ZFR alone) and MP (two subjects playing ZFR simultaneously). Heart rate (HR), oxygen consumption $\left(\mathrm{VO}_{2}\right)$ and $\mathrm{EE}\left(\mathrm{MET}\right.$ and $\left.\mathrm{kcal} \cdot \mathrm{min}^{-1}\right)$ were continuously measured and averaged every 10 seconds, while Rating of Perceived Exertion (RPE) was recorded 30 minutes after the end of each session. A two (gender: women vs. men) by two (modality: SP vs. MP) ANOVA for repeated measures was applied. No differences emerged in relation to gender and game mode for $\% \mathrm{HRmax}, \mathrm{VO}_{2}, \mathrm{MET}$, and RPE. Conversely, the main effect $(\mathrm{p}=.0007)$ for gender was found in EE, with significantly $(\mathrm{p}<.004)$ higher values in men in SP (women: $5.5 \pm 0.6 \mathrm{kcal} \cdot \mathrm{min}^{-1}$; men: $8.3 \pm 1.4 \mathrm{kcal} \cdot \mathrm{min}^{-1}$ ) and MP (women: $5.3 \pm 0.7 \mathrm{kcal} \cdot \mathrm{min}^{-1}$; men: $7.6 \pm 1.9$ $\left.\mathrm{kcal} \cdot \mathrm{min}^{-1}\right)$. Present findings suggest that ZFR could be classified as a moderate physical activity, proving to be an alternative form to traditional exercise. Although an effect of number of players could be expected, different player modes did not affect EE, probably because the rhythm of the music imposes a time constraint, independently of the presence of other players.
\end{abstract}

Key words: exergame, physical activity, cardiovascular responses, heart rate, oxygen consumption, zumba

\section{Introduction}

Sedentary behaviors are responsible each year for more than five million deaths (Hallal, et al., 2012). Regular participation in physical activity is associated with numerous physiological and psychological health benefits across lifetime ages (American College of Sports Medicine [ACSM], 2014; Gallagher, Zelestis, Hollams, Denney-Wilson, \& Kirkness, 2013; Hamer \& Stamatakis, 2012; World Health Organization [WHO], 2014), and about half a million deaths might be prevented if sedentary behaviors would decrease by approximately $10 \%$ (Lee, et al., 2012). Although for healthy adults aged 18-65 years ACSM recommends from 75 to 150 minutes of weekly exercise at a moderate inten- sity (ACSM, 2014) to maintain cardiorespiratory, musculoskeletal, and neuromotor fitness, about two third of adults and only $20 \%$ of adolescents worldwide reach the recommended levels of daily physical activity (Hallal, et al., 2012).

Despite video gaming has been partially accused for the fast increase in sedentary behaviors, active video games (or exergames, AVGs) provide encouragement to exercise, particularly for those who may be reluctant to engage in more traditional forms of exercise (Whitehead, Johnston, Nixon, \& Welch, 2010). Comparing a traditional aerobic activity as stationary bike with the Gamebike ${ }^{\mathbb{B}}$ AVG, Warburton et al. (2007) highlighted that the use of AVG increased the adherence to the prac- 
tice of physical activity about $30 \%$ with respect to traditional one. Therefore, AVGs can represent a potentially innovative strategy to promote enjoyment of physical activity (Bailey \& McInnis, 2011), by eliciting light-to-vigorous intensity exercise and contributing to health enhancing physical activity (Monedero, Murphy, \& O'Gorman, 2017).

Research showed that AVGs can significantly increase energy expenditure (EE) and physical activity compared to sedentary video games (Graves, et al., 2010), proving to be a suitable alternative to traditional play or moderate-intensity physical activity in teen (Clevenger \& Howe, 2015) and young men (Barry, et al., 2016). Considering the popularity of Zumba ${ }^{\circledR}$ Classes (ZC) among fitness activities (Thompson, 2011, 2012), several AVGs and DVDs have been developed. In particular, XBOX Kinect 360 has released different AVGs, such as Zumba ${ }^{\circledR}$ Fitness, Zumba ${ }^{\circledR}$ Fitness Rush (ZFR) and Zumba ${ }^{\circledR}$ Fitness Core. Evaluating acute cardiovascular response in Zumba ${ }^{\circledR}$ Fitness Core, Neves et al. (2015) showed increased heart rate (HR, $112.7 \pm 14.1$ vs. $67.7 \pm 7.3$ beats $\cdot \mathrm{min}^{-1}$ ) and systolic $(136.2 \pm 17.9$ vs. $115.4 \pm 13.3 \mathrm{mmHg})$ and diastolic $(80.0 \pm 10.9$ vs. $70.5 \pm 7.4 \mathrm{mmHg})$ blood pressure. Howe, Barr, Winner, Kimble, and White (2015) showed in Zumba ${ }^{\circledR}$ Fitness AVG an average exercise HR of 139 beats min $^{-1}$, oxygen consumption $\left(\mathrm{VO}_{2}\right)$ above resting of $19.6 \mathrm{ml} \cdot \mathrm{kg}^{-1} \cdot \mathrm{min}^{-1}$ and $\mathrm{EE}$ of 7.4 MET and $6.8 \mathrm{kcal} \cdot \mathrm{min}^{-1}$. Delextrat and Neupert (2016) compared ZC to Zumba ${ }^{\circledR}$ DVD, showing higher HR (78.3 \pm 5.4 vs. $73.8 \pm 6.7 \% \mathrm{HRpeak}), \mathrm{VO}_{2}$ (66.0 \pm 9.6 vs. $\left.55.1 \pm 12.8 \% \mathrm{VO}_{2} \max \right)$, and $\mathrm{EE}(6.8 \pm 0.9$ vs. $5.6 \pm 0.9 \mathrm{kcal} \cdot \mathrm{min}^{-1}$ and $7.4 \pm 1.1$ vs. $6.0 \pm 1.2 \mathrm{MET}$ ) values in ZC with respect to Zumba ${ }^{\circledR}$ DVD.

In particular, considering that sedentary video games elicit EE about one MET (Barry, et al., 2016; Graves, et al., 2010), researchers (Ainsworth, et al., 2011; Barry, et al., 2016; Graves, et al., 2010) highlighted that AVGs can be classified as light intensity $\left(<3.0\right.$ MET, i.e., Wii Fit ${ }^{\circledR}$ balance, Wii $\mathrm{Fit}^{\circledR}$ boxing, Wii Fit ${ }^{\circledR}$ yoga, Wii Fit ${ }^{\circledR}$ muscle conditioning), moderate intensity (3.0-5.9 MET, i.e., Wii $\mathrm{Fit}^{\circledR}$ aerobic exercise, Wii Fit ${ }^{\circledR}$ resistance exercise, Wii Fit ${ }^{\circledR}$ strength exercise, Dance Dance Revolu$\operatorname{tion}^{\circledR}$ for novice people, bike for Xrtainment Zone, boxing for Xrtainment Zone, 3-Kick for Xrtainment Zone) and vigorous intensity ( $>6.0$ MET, i.e., Boxing for Xbox Kinect, Reflex Ridge for Xbox Kinect, River Rush for Xbox Kinect, Dance Dance Revolution ${ }^{\circledR}$ with self-selected or level four difficulty) activities according to ACSM's guidelines (ACSM, 2014).

As psychological factors such as fun and enjoyment are direct determinants of engagement in physical activity (Cortis, et al., 2017), given the presence of a group class, ZC could be perceived as more enjoyable with respect to a DVD, thus resulting in an increased EE. As two different playing modalities of ZFR exist, a singleplayer (SP) and a multiplayer (MP) one, it could be speculated that playing with a partner might be perceived as more engaging than playing alone, thus resulting in a possible increase in EE similar to regular group activities. During SP, a player plays solo with (or against) the artificial intelligence designed into the game, while in MP he/she plays with (or against) real persons. Although several AVG consoles allow playing in SP or MP mode, relatively few studies investigated differences with respect to modality. In particular, O'Donovan et al. (2012) compared two different AVGs (Reflex Ridge for Xbox Kinect and Sports Boxing for Wii) played for 10 minutes in SP and MP modes. Results reported higher HR and EE values when participants played in MP than in SP mode in both Reflex Ridge ( $118 \pm 20$ vs. $114 \pm 21$ beats $\mathrm{min}^{-1}$ and $7.2 \pm 2.1$ vs. $\left.6.8 \pm 1.8 \mathrm{kcal} \cdot \mathrm{min}^{-1}\right)$ and Sports Boxing (119 \pm 28 vs. $107 \pm 28$ beats $\cdot \mathrm{min}^{-1}$ and $6.1 \pm 2.3$ vs. $\left.5.0 \pm 1.5 \mathrm{kcal} \cdot \mathrm{min}^{-1}\right)$ AVGs. Peng and Crouse (2013), using Space Pop mini-game in Kinect Adventures for Xbox Kinect, showed that playing in MP mode increased enjoyment and motivation when compared to SP mode, adding that the best results were found when participants played in parallel in different spaces. Moreover, Verhoeven, Abeele, Gers, and Seghers (2015) evaluated $\mathrm{EE}$ and enjoyment in children in six different AVGs, showing overall higher EE values in MP mode with respect to SP, although no differences in enjoyment emerged. Conversely, Mackintosh, Standage, Staiano, Lester, and McNarry (2016) showed no differences in EE and psychological responses between SP and MP playing $\mathrm{Wii}^{\mathrm{TM}}$ Boxing, with men reporting higher EE values and women showing better psychological responses, regardless of playing modality. Moreover, evaluating gender differences in AVG's perceived enjoyment in adolescents, boys reported enjoying competitive games, whereas girls preferred dance games (Bailey \& McInnis, 2011).

Since the effects of playing modality have been investigated with AVGs practiced as leisure time physical activity played for a short time (i.e., $\leq 30$ minutes; O'Donovan, et al., 2012; Mackintosh, et al., 2016; Monedero, et al., 2017; Verhoeven, et al., 2015), the aim of this study was to evaluate the psycho-physiological (i.e., $\mathrm{HR}, \mathrm{VO}_{2}$, EE and Rating of Perceived Exertion [RPE]) responses to AVG as a form of a workout played in SP and MP mode, also in relation to gender, by hypothesizing that: 1) MP mode could increase psycho-physiological demands when compared to SP mode, and 2) men could report higher psycho-physiological values than women. 


\section{Methods}

\section{Participants}

Twenty-four (14 women [age $24.4 \pm 1.5$ years; body weight: $51.2 \pm 3.9 \mathrm{~kg}$; body height: $160.3 \pm 4.5$ $\mathrm{cm}$; BMI: $19.9 \pm 1.0 \mathrm{~kg} \cdot \mathrm{m}^{-2}$ ] and 10 men [age: $24.8 \pm 2.6$ years; body weight: $72.8 \pm 8.5 \mathrm{~kg}$; body height: 178.4 $\pm 9.7 \mathrm{~cm}$; BMI: $\left.22.9 \pm 2.2 \mathrm{~kg} \cdot \mathrm{m}^{-2}\right]$ ) college students, with no previous experience in ZFR, volunteered to participate in the study. Participants were excluded if they reported any preexisting condition such as cardiovascular, respiratory and/or metabolic diseases or physical injuries. Before the beginning of the study, approved by the local Institutional Review Board, written informed consent was obtained from all participants in accordance with the Declaration of Helsinki for Human Research of 1964.

\section{Preliminary assessments}

Maximal aerobic power $\left(\mathrm{VO}_{2 \max }\right)$ and level of physical activity were evaluated before the experimental sessions. $\mathrm{VO}_{2 \max }$ was estimated by the Queens College Step Test (Sadhan, Koley, \& Sandhu, 2007). The test required stepping up and down a $41.3 \mathrm{~cm}$ step for a total of three minutes. Metronome was used to monitor the stepping cadence, which was set at 88 beats $\cdot \mathrm{min}^{-1}\left(22\right.$ steps $\left.\cdot \mathrm{min}^{-1}\right)$ for women and 96 beats $\cdot \mathrm{min}^{-1}\left(24\right.$ steps $\left.\cdot \mathrm{min}^{-1}\right)$ for men. After completion of the test, the carotid pulse rate was measured for 15 seconds, from the fifth to the $20^{\text {th }}$ second $\left(\mathrm{HR}_{\mathrm{QCST}}\right)$ of the recovery period. $\mathrm{VO}_{2 \max }$ $\left(\mathrm{ml} \cdot \mathrm{kg}^{-1} \cdot \mathrm{min}^{-1}\right)$ was then calculated by means of the following equations (Sadhan, et al., 2007):

$$
\begin{aligned}
& \text { Woman: } \mathrm{VO}_{2 \max }=65.81-\left[0.1847 \cdot\left(\mathrm{HR}_{\mathrm{QCST}} \cdot 4\right)\right] \text {; } \\
& \text { Man: } \mathrm{VO}_{2 \max }=111.33-\left[0.42 \cdot\left(\mathrm{HR}_{\mathrm{QCST}} \cdot 4\right)\right] \text {. }
\end{aligned}
$$

Results showed the estimated $\mathrm{VO}_{2 \max }$ values of $38.1 \pm 4.5 \mathrm{ml} \cdot \mathrm{kg}^{-1} \cdot \mathrm{min}^{-1}$ and $51.9 \pm 8.9 \mathrm{ml} \cdot \mathrm{kg}^{-1} \cdot \mathrm{min}^{-1}$ for women and men, respectively.

Level of physical activity was evaluated through using a short version (7 items) of the Italian version of the International Physical Activity Questionnaire (Mannocci, et al., 2010). Women reported 8.3 \pm 5.3 hours.week ${ }^{-1}$ of vigorous and $2.5 \pm 3.3$ hours'week ${ }^{-1}$ of moderate activities, while men reported $6.2 \pm 2.6$ hours'week ${ }^{-1}$ of vigorous and 3.1 \pm 5.4 hours'week $^{-1}$ of moderate activities.

\section{Procedures}

Since the participants included in the study were novice to ZFR, three group familiarization sessions were administered to ensure an adequate training with the ZFR choreography and avoid any potential learning effect on the results. Participants played the 50-minute XBOX Kinect 360
ZFR (lesson one, middle version) in the Sport and Exercise Physiology laboratory during two experimental sessions, organized with at least two days in between: SP (with the participant playing the AVG alone) and MP (with two participants playing the AVG simultaneously) modes randomly assigned. During the game, two telemetric open-circuit measurement systems ( $\mathrm{K}_{4} \mathrm{~b}^{2}$, Cosmed, Rome, Italy) were used to continuously record HR response (Polar T31 transmitter, Polar Electro, Kempele, Finland) and $\mathrm{VO}_{2}$, averaged every 10 seconds. HR data were subsequently expressed as percentages of individual theoretical maximal HR (209-0.7 age; \%HRmax; Tanaka, Monahan, \& Seals, 2001). K4 $\mathrm{b}^{2}$ estimates EE by measuring breath-by-breath oxygen uptake and converts it to kilocalories per minute $(\mathrm{kcal} \cdot \mathrm{kg}$ ${ }^{1} \cdot \mathrm{min}^{-1}$ ) using the Haldane correction for inspired minute ventilation and standard equations (Harrell, et al., 2005). Before each experimental session, known gas mixtures $\left(\mathrm{O}_{2}: 16.0 \%\right.$ and $20.9 \% ; \mathrm{CO}_{2}$ : $5.0 \%$ and $0.03 \%$ ) were used to calibrate the gas analyzer, while a 3-liter syringe (Hans Rudolph Inc, Dallas, USA) was used to calibrate the flow meter. $\mathrm{K}_{4} \mathrm{~b}^{2}$ showed intraclass reliability coefficients (ICC) ranging from .7 to .9 (Duffield, Dawson, Pinnington, \& Wong, 2004). To monitor exercise intensity, RPE was recorded by means of the Category-Ratio 10 Scale (Foster, Heimann, Esten, Brice, $\&$ Porcari, 2001). RPE was collected approximately 30 minutes after the end of the session to ensure that the perceived exertion referred to the whole session rather than to the most recent exercise intensity.

\section{Statistical analysis}

Means and standard deviations were calculated for all data. Statistical significance was set at $\mathrm{p}<.05$. A two (gender: women vs. men) by two (modality: SP vs. MP) analysis of variance (ANOVA) for repeated measures was applied to $\% \mathrm{HRmax}, \mathrm{VO}_{2}$, MET, EE and RPE values. If the overall $F$ test was significant, the post-hoc Fisher protected least significant difference comparisons were used.

\section{Results}

Data regarding subjective evaluations, cardiovascular and metabolic parameters are presented in Table 1.

No significant differences emerged for \%HRmax, $\mathrm{VO}_{2}$, MET and RPE in relation to either gender or playing modality. Conversely, a main effect $(\mathrm{p}=.0007)$ for gender was found in $\mathrm{EE}$, with the post-hoc analysis showing significantly $(\mathrm{p}<.004)$ higher values in men in both the SP (women: $5.5 \pm 0.6 \mathrm{kcal} \cdot \mathrm{min}^{-1}$; men: $8.3 \pm 1.4$ $\mathrm{kcal} \cdot \mathrm{min}^{-1}$ ) and MP (women: $5.3 \pm 0.7 \mathrm{kcal} \cdot \mathrm{min}^{-1}$; men: $\left.7.6 \pm 1.9 \mathrm{kcal} \cdot \mathrm{min}^{-1}\right)$ mode. 
Table 1. Mean and standard deviation of physiological and psychological parameters measured during Zumba ${ }^{\circledR}$ Fitness Rush played in single (SP) and multiplayer (MP) mode

\begin{tabular}{lcccccc}
\hline & \multicolumn{2}{c}{ Women } & \multicolumn{2}{c}{ Men } & \multicolumn{2}{c}{ Total } \\
\cline { 2 - 7 } & SP & MP & SP & MP & SP & MP \\
\hline HRmax (\%) & $73.5 \pm 6.8$ & $72.3 \pm 7.1$ & $72.4 \pm 8.4$ & $67.5 \pm 11.5$ & $73.1 \pm 7.3$ & $70.5 \pm 9.0$ \\
VO $_{2}\left(\mathrm{ml} \cdot \mathrm{kg}^{-1} \cdot \mathrm{min}^{-1}\right)$ & $22.4 \pm 2.1$ & $21.5 \pm 2.9$ & $21.9 \pm 4.2$ & $20.1 \pm 5.3$ & $22.2 \pm 3.0$ & $20.9 \pm 3.9$ \\
EE $(\mathrm{METs})$ & $6.4 \pm 0.6$ & $6.2 \pm 0.8$ & $6.3 \pm 1.2$ & $5.7 \pm 1.5$ & $6.3 \pm 0.9$ & $6.0 \pm 1.1$ \\
EE $\left(\mathrm{kcal} \cdot \mathrm{min}^{-1}\right)$ & $5.5 \pm 0.6$ & $5.3 \pm 0.7$ & $8.3 \pm 1.4^{*}$ & $7.6 \pm 1.9^{*}$ & $6.7 \pm 1.7$ & $6.2 \pm 1.7$ \\
RPE & $4.4 \pm 2.1$ & $4.7 \pm 1.9$ & $4.2 \pm 1.1$ & $4.6 \pm 1.8$ & $4.3 \pm 1.7$ & $4.7 \pm 1.8$ \\
\hline
\end{tabular}

Note. HRmax: maximal heart rate; $\mathrm{VO}_{2}$ : oxygen consumption; EE: energy expenditure; RPE: rating of perceived exertion.

* = significantly $(p<.004)$ higher than women.

\section{Discussion and conclusions}

The main findings of the present study are that 1) no difference emerged in psycho-physiological responses in AVG played in SP and MP mode, and 2) men showed higher EE regardless of game mode.

In contrast to O'Donovan et al. (2012), no differences for HR and EE emerged between exercise modalities. Recent studies showed contrast findings, proving that different games could elicit different responses. O'Donovan et al. (2012) found higher values in MP mode than SP, while Mackintosh et al. (2016) showed no differences. In a sample of children, Verhoeven et al. (2015) found higher EE in MP than SP mode when participants played boxing (SP: 6.3 \pm 1.4 MET; MP: 7.0 \pm 1.6 MET), tennis (SP: 3.9 \pm 0.9 MET; MP: $4.7 \pm 1.2$ MET), and dancing (SP: 5.3 \pm 1.1 MET; MP: $5.8 \pm 1.1$ MET), higher EE values in SP compared to MP when children played bowling (SP: $3.8 \pm 0.8 \mathrm{MET}$; MP: $3.3 \pm 0.5 \mathrm{MET}$ ), and no difference when playing golf (SP: $2.9 \pm 0.9$ MET; MP: $2.9 \pm 0.8 \mathrm{MET}$ ) and baseball (SP: $4.0 \pm 1.0 \mathrm{MET}$; MP: 4.1 $\pm 0.8 \mathrm{MET})$, concluding that non-parallel duo-play (i.e., when one player creates or functions as a direct obstacle to the other player who needs to overcome this obstacle) might be best suited to increase levels of physical activity in inactive early adolescents.

When comparing different studies and games, it has to be taken into consideration whether the SP mode was a truly SP. In fact, the player could play in SP mode by competing against a computer-generated opponent, or merely focus on his/her performance only. In particular, Staiano and Calvert (2011) reported higher EE in children playing against peers rather than virtual characters. Therefore, players could never really have had a competitive gaming experience (Peng, Lin, \& Crouse, 2011; Staiano \& Calvert, 2011). ZFR could be considered as a parallel play in which one player has no direct influence upon the difficulty of the task faced by the opponent. During ZFR the player follows the instructors' clues and the choreography, collecting stars when playing well, thus increasing the score (percentage of success). Also, before every move- ment change, the player receives a visual cue of the next movement few seconds before the change, thus he/she can follow the instructor in due time, without feeling lost with the choreography (Zanardi de Toledo, 2014). As in this study no difference emerged between game modes, it could be speculated that the rhythm of the music in ZFR plays the key role, imposing a time constraint to the performer, who follows the instructor and the choreography rather than focusing on beating his/her counterpart. In fact, similar percentage of success emerged when playing SP $(77.3 \pm 10.1 \%)$ and MP ( $75.9 \pm 11.2 \%)$, thus indicating a similar engagement (and effort) regardless of the modality.

In line with a previous study (Mackintosh, et al., 2016), gender-related differences were found in EE regardless of game modality, with higher values in men than women. Since no difference emerged in $\mathrm{VO}_{2}$, the higher EE found in men could be due to their heavier body mass (mean difference around 20 $\mathrm{kg}$ ). Although it has been suggested that untrained women may have a relatively higher EE than men when performing intense muscular contraction (Mattei, Bendahan, Roussel, Lefur, \& Cozzone, 1999), in the present study a moderate intensity activity was performed, thus opposite results emerged. Moreover, as previously reported (KentBraun, Ng, Doyle, \& Towse, 2002), it is possible that women may rely relatively more on aerobic EE (and consequently less on anaerobic energy) and men more on anaerobic EE, thus explaining the higher EE found in men during the aerobic-based ZFR activity. Although showing lower values of estimated $\mathrm{VO}_{2 \max }$, in this study women reported high amounts of weekly vigorous activities, and in addition to their natural preference toward dance activity (Bailey \& McInnis, 2011; Mackintosh, et al., 2016) with respect to men, these aspects could contribute to explaining the gender-related differences emerged in EE.

In line with laboratory studies (Peng, Crouse, \& Lin, 2013), the present findings suggest that ZFR, regardless of playing modality, could be classified as a moderate-intensity exercise (ACSM, 2014). There- 
fore, ZFR could be an alternative form to traditional exercise, especially when considering that AVGs may be perceived less strenuous and more enjoyable than traditional programs, even when total EE is similar (Brumels, Blasius, Cortright, Oumedian, $\&$ Solberg, 2008). Moreover, the light-to-moderate intensity elicited is in line with the recommended physical activity for older adults, making AVGs a more suitable tool for older adults than for children (Peng, et al., 2013).

This study showed lower $\mathrm{HR}, \mathrm{VO}_{2}$, and $\mathrm{EE}$ in ZFR when compared to ZC (Delextrat \& Neupert, 2016; Luettgen, Foster, Doberstein, Mikat, \& Porcari, 2012). Similar HR responses were found in ZFR with respect to Zumba ${ }^{\circledR}$ Fitness (Howe, et al., 2015) and Zumba ${ }^{\circledR}$ DVD (Delextrat \& Neupert, 2016), whereas lower $\mathrm{VO}_{2}$ and $\mathrm{EE}$ were recorded with respect to Zumba ${ }^{\circledR}$ Fitness (Howe, et al., 2015) and Zumba ${ }^{\circledR}$ DVD (Delextrat \& Neupert, 2016).

Regarding EE, MET values emerged to be higher than different Wii Fit ${ }^{\circledR}$ AVGs (yoga, balance, yoga chair, yoga warrior, boxing, resistance exercise, aerobic exercise, aerobics, and strength), kick (3-Kick) and bike (Disney's Cars Piston Cup Race) games, comparable to Kinect Adventures (River Rush) and sports (Boxing) games, and lower than Dance Dance Revolution for expert subjects and Kinect Adventures (Reflex Ridge) game (Barry, et al., 2016; Ainsworth, et al., 2011). When expressing data in kcal'hour ${ }^{-1}$, results of this study showed that one hour of ZFR allow to burn about 320 and 460 kcal in women and men, respectively. Since ACSM guidelines suggest reaching at least $300 \mathrm{kcal}$ per training session to maintain a healthy lifestyle (ACSM, 2014), ZFR might represent a valuable alternative to traditional physical activity such as brisk treadmill walking (Graves, et al., 2010).

Based on RPE values, subjects perceived ZFR as a moderate-to-hard intensity exercise (Foster, et al., 2001). Similar results were found in $\mathrm{ZC}$ by Hausken and Dyrstad (2013) using the 6-20 RPE scale. Lower values were recorded by Barry et al. (2016) in three different AVGs (11 \pm 2 in River Rush, $12 \pm 2$ in Boxing, and $13 \pm 2$ in Reflex Ridge on the 6-20 RPE scale, corresponding to 2.0, 3.0 and 3.5 on Category-Ratio 10 Scale) than in ZFR.

In conclusion, the results of this study suggest that there are no differences when playing AVG in SP or MP mode. Even though lower physiological responses were found when compared to traditional ZC, ZFR could be used to contrast sedentary behaviors, considering that this activity reached the EE levels suggested by the ACSM guidelines (2014). Since MP mode could increase motivation and enjoyment, further studies should evaluate differences in relation to number of players (two vs. three vs. four), age, motivation and enjoyment of these activities.

Some limitations should be acknowledged for this study: the sample size was relatively small, but in line with recent similar research studies; only young sample was analyzed. In the MP mode, only double players were tested, while XBOX Kinect allows up to four participants playing meantime.

\section{References}

Ainsworth, B.E., Haskell, W.L., Herrmann, S.D., Meckes, N., Bassett, D.R., Tudor-Locke, C., Greer, J.L., Vezina, J., Whitt-Glover M.C., \& Leon, A.S. (2011). 2011 Compendium of physical activities: A second update of codes and MET values. Medicine and Science in Sports and Exercise, 43(8), 1575-1581. doi:10.1249/MSS.0b013e31821ece12

American College of Sports Medicine. (2014). ACSM's guidelines for exercise testing and prescription ( $9^{\text {th }}$ edition). Philadelphia, PA: Lippincott, Williams \& Wilkins.

Bailey, B.W., \& McInnis, K. (2011). Energy cost of exergaming: A comparison of the energy cost of 6 forms of exergaming. Archives of Pediatrics and Adolescent Medicine, 165(7), 597-602. doi:10.1001/archpediatrics.2011.15

Barry, G., Tough, D., Sheerin, P., Mattinson, O., Dawe, R., \& Board, E. (2016). Assessing the physiological cost of active videogames (Xbox Kinect) versus sedentary videogames in young healthy males. Games for Health Journal, 5(1), 68-74. doi:10.1089/g4h.2015.0036

Brumels, K.A., Blasius, T., Cortright, T., Oumedian, D., \& Solberg, B. (2008). Comparison of efficacy between traditional and video game based balance programs. Clinical Kinesiology: Journal of the American Kinesiotherapy Association, 62(4), 26-32.

Clevenger, K.A., \& Howe, C.A. (2015). Energy cost and enjoyment of active videogames in children and teens: Xbox 360 Kinect. Games for Health Journal, 4(4), 318-324. doi:10.1089/g4h.2014.0101

Cortis, C., Puggina, A., Pesce, C., Aleksovska, K., Buck, C., Burns, C., et al. (2017). Psychological determinants of physical activity across the life course: A "DEterminants of DIet and Physical ACtivity" (DEDIPAC) umbrella systematic literature review. PLoS ONE 12(8), e0182709. doi:10.1371/journal.pone.0182709

Delextrat, A., \& Neupert, E. (2016). Physiological load associated with a Zumba ${ }^{\circledR}$ fitness workout: A comparison pilot study between classes and a DVD. Journal of Sports Sciences, 34(1), 47-55. doi:10.1080/02640414.2015.1031162 
Duffield, R., Dawson, B., Pinnington, H.C., \& Wong, P. (2004). Accuracy and reliability of a Cosmed K4b2 portable gas analysis system. Journal of Science and Medicine in Sport, 7(1), 11-22. doi:10.1016/S1440-2440(04)80039-2

Foster, C., Heimann, K.M., Esten, P.L., Brice, G., \& Porcari, J.P. (2001). Differences in perceptions of training by coaches and athletes. South African Journal of Sports Medicine, 8(2), 3-7.

Gallagher, R., Zelestis, E., Hollams, D., Denney-Wilson, E., \& Kirkness, A. (2013). Impact of the healthy eating and exercise lifestyle programme on depressive symptoms in overweight people with heart disease and diabetes. European Journal of Preventive Cardiology, 21(9), 1117-1124. doi:10.1177/2047487313486043

Graves, L.E.F., Ridgers, N.D., Williams, K., Stratton, G., Atkinson, G., \& Cable, N.T. (2010). The physiological cost and enjoyment of Wii Fit in adolescents, young adults, and older adults. Journal of Physical Activity and Health, 7(3), 393-401. doi:10.1123/jpah.7.3.393

Hallal, P.C., Andersen, L.B., Bull, F.C., Guthold, R., Haskell, W., Ekelund, U., \& Lancet Physical Activity Series Working Group. (2012). Global physical activity levels: Surveillance progress, pitfalls, and prospects. Lancet, 380(9838), 247-257. doi:10.1016/S0140-6736(12)60646-1

Hamer, M., \& Stamatakis, E. (2012). Low-dose physical activity attenuates cardiovascular disease mortality in men and women with clustered metabolic risk factors. Circulation: Cardiovascular Quality and Outcomes, 5(4), 494-499. doi:10.1161/CIRCOUTCOMES.112.965434

Harrell, J.S., Mcmurray, R.G., Baggett, C.D., Pennell, M.L., Pearce, P.F., \& Bangdiwala, S.I. (2005). Energy costs of physical activities in children and adolescents. Medicine and Science in Sports and Exercise, 37(2), 329-336. doi:10.1249/01.MSS.0000153115.33762.3F

Hausken, K., \& Dyrstad, S.M. (2013). Heart rate, accelerometer measurements, experience and rating of perceived exertion in Zumba, interval running, spinning, and pyramid running. Journal of Exercise Physiology Online, 16(6), 39-50.

Howe, C.A., Barr, M.W., Winner, B.C., Kimble, J.R., \& White, J.B. (2015). The physical activity energy cost of the latest active video games in young adults. Journal of Physical Activity and Health, 12(2), 171-177. doi:10.1123/ jpah.2013-0023

Kent-Braun, J.A., Ng, A.V., Doyle, J.W., \& Towse, T.F. (2002). Human skeletal muscle responses vary with age and gender during fatigue due to incremental isometric exercise. Journal of Applied Physiology, 93(5), 1813-1823. doi: 10.1152/japplphysiol.00091.2002

Lee, I.M., Shiroma, E.J., Lobelo, F., Puska, P., Blair, S.N., Katzmarzyk, P.T., \& Lancet Physical Activity Series Working Group. (2012). Effect of physical inactivity on major non-communicable diseases worldwide: An analysis of burden of disease and life expectancy. Lancet, 380(9838), 219-229. doi:10.1016/S0140-6736(12)61031-9

Luettgen, M., Foster, C., Doberstein, S., Mikat, R., \& Porcari, J. (2012). Zumba ${ }^{\circledR}$ : Is the "fitness-party" a good workout? Journal of Sports Science and Medicine, 11(2), 357-358.

Mackintosh, K.A., Standage, M., Staiano, A.E., Lester, L., \& McNarry, M.A. (2016). Investigating the physiological and psychosocial responses of single- and dual-player exergaming in young adults. Games for Health Journal, 5(6), 375-381. doi:10.1089/g4h.2016.0015.

Mannocci, A., Di Thiene, D., Del Cimmuto, A., Masala, D., Boccia, A., De Vito, E., \& La Torre, G. (2010). International Physical Activity Questionnaire: Validation and assessment in an Italian sample. Italian Journal of Public Health, 7(4), 369-376. doi:10.2427/5694.

Mattei, J.P., Bendahan, D., Roussel, M., Lefur, Y., \& Cozzone, P.J. (1999). Gender modulates the energy cost of muscle contraction in untrained healthy subjects. A 31P magnetic resonance spectroscopy analysis. Federation of European Biological Societies Letters, 450(3), 173-177. doi:10.1016/S0014-5793(99)00503-7.

Monedero, J., Murphy, E.E., \& O’Gorman, D.J. (2017). Energy expenditure and affect responses to different types of active video game and exercise. PloS One, 12(5), e0176213. doi:10.1371/journal.pone.0176213.

Neves, L.E.D.S., Cerávolo, M.P.D.S., Silva, E., De Freitas, W.Z., Da Silva, F.F., Higino, W.P., Carvalho, W.R., \& De Souza, R.A. (2015). Cardiovascular effects of $\mathrm{Zumba}^{\circledR}$ performed in a virtual environment using XBOX Kinect. Journal of Physical Therapy Science, 27(9), 2863-2865. doi:10.1589/jpts.27.2863

O’Donovan, C., Hirsch, E., Holohan, E., McBride, I., McManus, R., \& Hussey, J. (2012). Energy expended playing Xbox Kinect ${ }^{\mathrm{TM}}$ and Wii ${ }^{\mathrm{TM}}$ games: A preliminary study comparing single and multiplayer modes. Physiotherapy, 98(3), 224-229. doi:10.1016/j.physio.2012.05.010

Peng, W., \& Crouse, J. (2013). Playing in parallel: The effects of multiplayer modes in active video game on motivation and physical exertion. Cyberpsychology, Behavior, and Social Networking, 16(6), 423-427. doi:10.1089/ cyber.2012.0384

Peng, W., Crouse, J.C., \& Lin, J.H. (2013). Using active video games for physical activity promotion: A systematic review of the current state of research. Health Education and Behavior, 40(2), 171-192. doi:10.1177/1090198112444956

Peng, W., Lin, J.H., \& Crouse, J. (2011). Is playing exergames really exercising? A meta-analysis of energy expenditure in active video games. Cyberpsychology, Behavior, and Social Networking, 14(11), 681-688. doi:10.1089/ cyber.2010.0578

Sadhan, B., Koley, S., \& Sandhu, J.S. (2007). Relationship between cardiorespiratory fitness, body composition and blood pressure in Punjabi collegiate population. Journal of Human Ecology, 22(3), 215-219.

Staiano, A.E., \& Calvert, S.L. (2011). Wii tennis play for low-income African American adolescents' energy expenditure. Cyberpsychology, 5(1). 
Tanaka, H., Monahan, K.D., \& Seals, D.R. (2001). Age-predicted maximal heart rate revisited. Journal of the American College of Cardiology, 37(1), 153-156. doi: 10.1016/S0735-1097(00)01054-8.

Thompson, W.R. (2011). Worldwide survey of fitness trends for 2012. ACSM's Health and Fitness Journal, 15(6), 9-18. doi:10.1249/FIT.0b013e31823373cb

Thompson, W.R. (2012). Worldwide survey of fitness trends for 2013. ACSM's Health and Fitness Journal, 16(6), 8-17. doi:10.1249/01.FIT.0000422568.47859.35

Verhoeven, K., Abeele, V.V., Gers, B., \& Seghers, J. (2015). Energy expenditure during Xbox Kinect play in early adolescents: The relationship with player mode and game enjoyment. Games for Health Journal, 4(6), 444-451. doi: 10.1089/g4h.2014.0106

Warburton, D.E., Bredin, S.S., Horita, L.T., Zbogar, D., Scott, J.M., Esch, B.T., \& Rhodes, R.E. (2007). The health benefits of interactive video game exercise. Applied Physiology, Nutrition, and Metabolism, 32(4), 655-663. doi: 10.1139/H07-038

Whitehead, A., Johnston, H., Nixon, N., \& Welch, J. (2010). Exergame effectiveness: What the numbers can tell us. Proceedings of the 5th ACM SIGGRAPH Symposium on Video Games - Sandbox '10, 55-62. doi:10.1145/1836135.1836144

World Health Organization (WHO). (2014). Physical Activity: Factsheet No. 385. Geneve: World Health Organization. Retrieved February 13, 2017, from http://www.who.int/mediacentre/factsheets/fs385/en/

Zanardi de Toledo, P. (2014). Study of Zumba game playing experience, related to previous knowledge of Zumba. (Master's thesis, University of Jyväskylä) Jyväskylä: Department of Art and Culture Studies. Retrieved February 13, 2017, from https://jyx.jyu.fi/dspace/handle/123456789/45587

Submitted: February 13, 2017

Accepted: January 24, 2018

Published Online First: March 12, 2018

Correspondence to:

Cristina Cortis, Ph.D.

Assistant Professor at the Department of Human

Sciences, Society and Health

University of Cassino e Lazio Meridionale

Via S. Angelo - Località Folcara

03043 Cassino (FR)

Tel: +3907762994436

Fax: +3907762993839

E-mail: c.cortis@unicas.it

\section{Acknowledgments}

The authors would like to express their gratitude to the participants involved in the study for their committed participation.

\section{Funding source}

No grant was received for this work. 